\title{
Auger Microscopy of Laser Induced Fe-oxide/Al Reaction Composite Coating
}

\author{
S. Nayak ${ }^{1}$, Harry M. Meyer, $\mathrm{III}^{2}$ and Narendra B. Dahotre ${ }^{1}$ \\ ${ }^{1}$ Dep. of Matl Sc. \& Engg, Center for Laser Applications, Univ. of Tennessee, Knoxville, TN, 37932 \\ ${ }^{2}$ High Temperature Materials Lab., Oak Ridge National Laboratory, Oak Ridge, TN, 37831
}

A laser-based technique is used to synthesize a $\mathrm{Fe}_{3} \mathrm{O}_{4} / \mathrm{Al}$ reaction composite coating on A319Al alloy. The material was analyzed using Scanning Auger Microprobe. The spectroscopy data indicated that several possible stoichiometric compounds formed as a result of chemical reaction between $\mathrm{Fe}_{3} \mathrm{O}_{4}$ and $\mathrm{Al}$. The elemental composition across the interface region, between such phases and the matrix, changes gradually suggesting that the interface is strong. Presence of $\mathrm{Al}_{2} \mathrm{O}_{3}$ in close vicinity of Fe-aluminide phase particles and thermodynamic data [1-3] suggests that both $\mathrm{Al}_{2} \mathrm{O}_{3}$ and $\mathrm{Fe}$ have been produced by metallothermic reaction. Fe has further reacted with $\mathrm{Al}$ to form $\mathrm{Fe}-$ aluminides.

Figure 1 is the secondary electron image of a typical particle-like feature. The Auger elemental analysis suggests that it is a Fe-rich phase. A closer look at the super-imposed line scan (normalized distribution of major elements) plotted across the line in the Fig. 1 indicated constant proportionality between $\mathrm{Fe}$ and $\mathrm{Al}$ concentration. In addition, the composition across the interface between such aluminide particle and the Al matrix changes gradually also often containing various stoichiometric and nonstoichiometric compositions of aluminides which is an indication of a strong interface. Moreover, such an in-situ synthesis of uniformly distributed fine aluminide particles having chemical bonding (via formation of interfacial aluminides) with the matrix are expected to produce the composite coating with superior mechanical properties compared to the $\mathrm{Al}$ - substrate.

Table 1 and schematic in Figure 2 summarizes the Auger microprobe results. Un-reacted and fragmented $\mathrm{Fe}_{3} \mathrm{O}_{4}$ particles were found in the fracture samples. Various reaction products residing near these particles were observed and included stoichiometric and non-stoichiometric phases. The Auger spectroscopy data taken on these phases was reduced to find stoichiometry by taking proportion of major elements present in different combinations for determination of the most likely phases. Fe-oxide particles present were found to have $\mathrm{Fe}$ to $\mathrm{O}$ atomic ratio between 1.1-1.3. In some particles, $\mathrm{Al}$ was present as high as $10 \mathrm{at} \%$ suggesting the $\mathrm{Al}$ has diffused into the oxide particle but quenched-in before reaction takes place. On the left side of the schematic in Figure 2, a particle like feature is represented. The ratio between $\mathrm{Fe}$ to $\mathrm{Al}$ was found to decrease gradually across the particle-matrix interface. Several point analysis on interface suggests that they may or may not be stoichiometric compound. The other particle-like features were $\mathrm{Al}_{2} \mathrm{O}_{3}$.

$>$ [1] T.B. Massalski, Binary Alloy Phase Diag., ASM Intl, Materials Park, Ohio, (1990) p147.

$>$ [2] Ralph Hultgren, et. al., Thermo. Prop. Bin. Alloys, ASM, Metals Park, Ohio, (1973), 156.

$>$ [3] V.W. Shevtsov, et. al. SSSR, Met., 1, (1981), 52.

$>$ Scanning Auger Microscope work sponsored by the Office of Transportation Technologies, (contract \# DE-AC05-00OR22725. 
Table 1: Summary of Auger spectroscopy data (Metals represents Fe, Al and Si)

\begin{tabular}{|c|c|c|c|c|c|}
\hline Location & Fe:Al & Metals:0 & 2AI:30 & $\begin{array}{c}\text { Possible } \\
\text { Stoichiometry }\end{array}$ & Remark \\
\hline Particle 1 & $0.9-1.1$ & High & 6.0-High & $\mathrm{FeAl}$ & \multirow{4}{*}{$\begin{array}{c}\text { Possibly } \\
\text { stoichiometry is } \\
\text { gradually } \\
\text { changing }\end{array}$} \\
\hline Particle 2 & 0.75 & High & 3.6 & FeAl (0.75Fe-Al) & \\
\hline Interface 1 & 0.66 & High & 4.9 & FeAl (0.66Fe-Al) & \\
\hline Interface 2 & $0.34-0.29$ & High & 5.7 & $\mathrm{FeAl}_{3}$ & \\
\hline Particle 3 & 0.41 & $0.9-1.0$ & 0.58 & $(\mathrm{Fe}, \mathrm{Si}, \mathrm{Al}) \mathrm{O}$ & Intermediate \\
\hline Particle 4 & $0.8-1.0$ & $3-4$ & $1.0-2.0$ & $\sim$ & Intermediate \\
\hline Particle 5 & $<0.2$ & $>0.8$ & $1-1.1$ & $\mathrm{Al}_{2} \mathrm{O}_{3}$ & \\
\hline Particle 6 & $>3$ & $1.1-1.3$ & $<0.1$ & $\mathrm{Fe}_{3} \mathrm{O}_{4}, \mathrm{FeO}$ & Unreacted \\
\hline Matrix & $0-0.1$ & $<0.05$ & $3-6$ & $\sim$ & Alloy \\
\hline
\end{tabular}

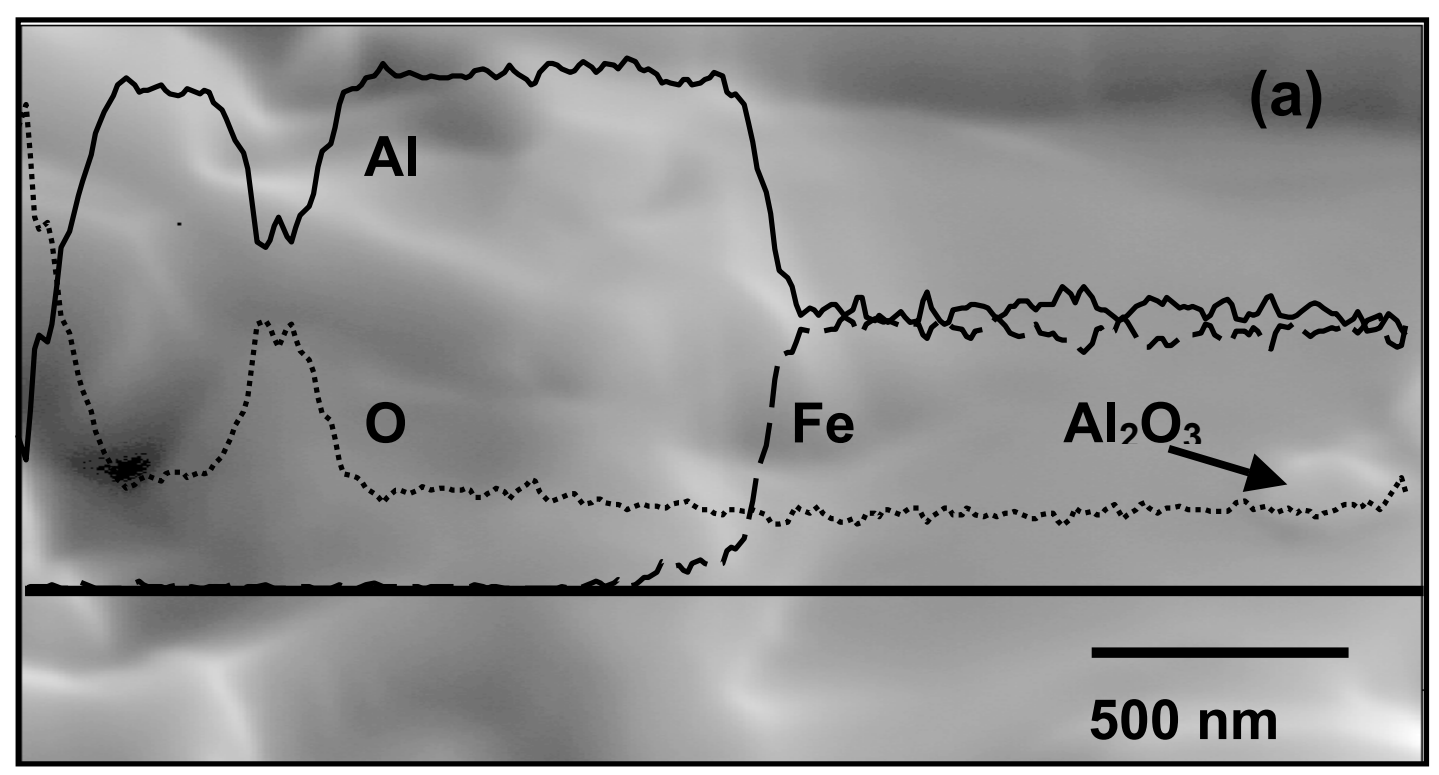

Fig 1: The secondary electron image of a particle like features composing of $\mathrm{Fe}, \mathrm{Al}$ and $\mathrm{O}$.

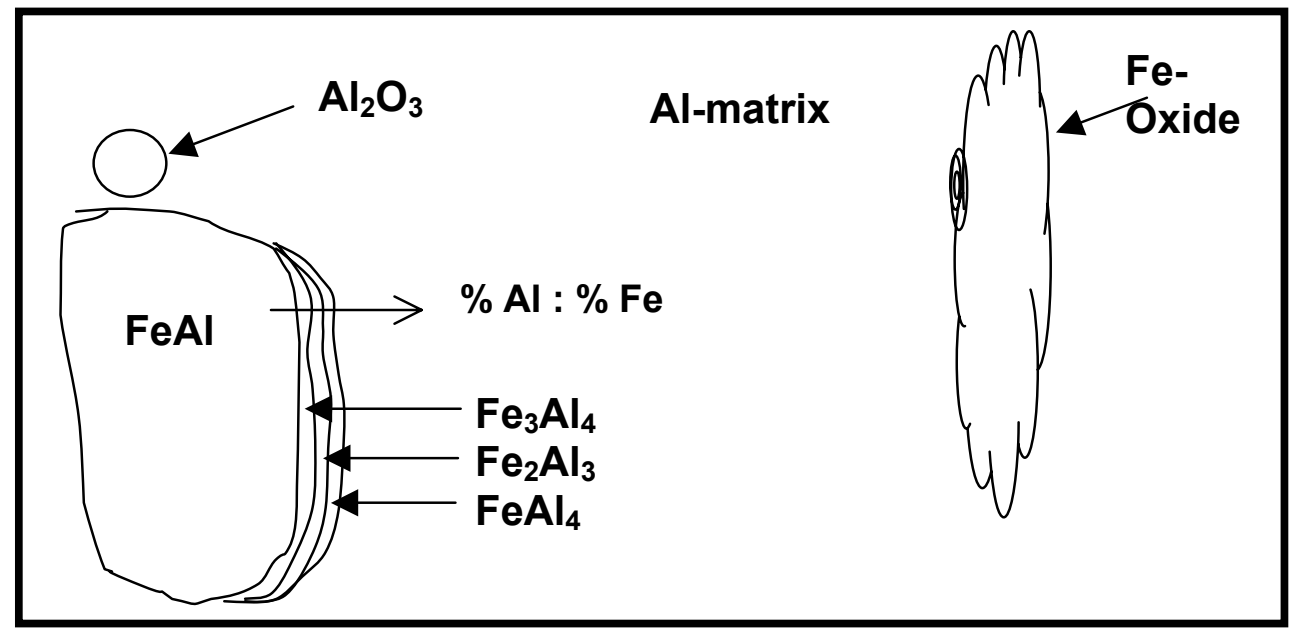

Figure 2: Schematic showing possible stoichiometric phases. Not to scale. 